\title{
The effect of disability on the needs of caregivers
}

Nerina Vecchio, Patti Cybinski, Stella Stevens

Nerina Vecchio

BA, BEc, MEcon, PhD (University of Queensland, Australia)

Lecturer

Griffith Business School

Griffith University Gold Coast Campus

PMB 50 Gold Coast Mail Center Queensland 9726 Australia

Tele: +61 755528284

Fax: +61 755528068

n.vecchio@griffith.edu.au

Patti Cybinski

BSc, MScSt, DipEd (University of Queensland, Australia), PhD (Griffith University, Australia)

Senior Lecturer

Stella Stevens

BA (Hons 1st Class) Sociology, PhD (Liverpool University, UK), Grad Cert RHD Supervision (Griffith University, Australia).

Senior Lecturer 


\title{
The effect of disability on the needs of caregivers
}

\begin{abstract}
Purpose - The perception among carers and health professionals is that the health care system remains limited in its effectiveness and accessibility to non-institutionalized people with a mental illness. The objective of this study is to determine the effect of the care recipient's main disabling condition (either physical or mental) on the carer's perceived need for assistance in their role as carer.

Design - Based on the data collected from the Australian Survey of Disability, Ageing and Carers, the investigation involved the non-institutionalized recipients of care with profound and severe disabilities, aged 15 years and over, residing in private dwellings and their primary informal carers.
\end{abstract}

Findings - Regression analysis revealed that carers of those with a mental disability were 2.7 times more likely to report care needs unmet compared to carers of those with a physical disability. Further analysis using interactions showed that carers who were the adult children of mentally disabled parents reported a comparatively very large amount of perceived unmet need.

Originality/value - If equity is measured in terms of perceived need rather than finite resources a case is made that primary carers of people with a mental disability experience greater burdens in care.

Keywords Disability, Informal caregiver, mental disability, physical disability, Australia

Paper type Research paper 


\section{Introduction}

Of particular concern to policy makers is the anticipated increase in costs associated with the care and support of a rapidly ageing Australian population (Australian Government Productivity Commission 2005). This has led to community care programs receiving increased attention as a cost-effective way of providing services for people in their own homes rather than in institutions (Healy 2002). The Australian deinstitutionalisation process, a shift in care from large-scale residential facilities to community based living arrangements, is now considered the norm for service provision of people with disabilities and has led to informal carers becoming the linchpin within community care programs (Queensland Government 2004; Kendig McVicar \& Reynolds 1992; Beilhorz Considine \& Watts 1992; Courtney Minichiello \& Wait 1997; Victorian Parliament, 1997). Although the development of effective health policies and planning for services in the home care setting require an understanding of carer availability, social and community support, little is known about informal carers, particularly those that care for people with a mental illness at home (Lefley 1996; Williams \& Doessel 2001).

Based on the data collected from the Australian Survey of Disability, Ageing and Carers (ABS 2003), the study reported here examines the impact of a recipient's disability type, either mental or physical, on a primary caregiver’s perceived need for assistance. The study is confined to primary carers of non-institutionalised recipients of care who are aged 15 years and over with either profound or severe core-activity limitations in communication, mobility and self-care. Since these recipients are the likely candidates for institutionalised care, an investigation of their carers is of particular interest given 
the policy push towards the de-institutionalization of the health care system. The objective of this study is to compare the perception of need of carers of people with a mental disability to those of carers of people with a physical disability. As such, it is based on subjective, though legitimate, measures.

Bradshaw's (1972) conception of need as either normative, perceived, expressed or relative is an established framework when considering human services. In the same way, perceived rather than medically assessed health status is also used as a legitimate measure of health by professionals through their use of the SF-36 need measurement tool (Ware et al 2000). Bradshaw's normative need refers to accepted standards with which resource allocation can be compared. Perceived need is what people think or feel their needs are, whilst expressed need is that most commonly used by economists to denote consumer behaviour in attempting to access a service. Relative need concerns disparities between one group and another (Bradshaw 1972). This study uses the perceived need of carers of individuals with either mental or physical disabilities as a measure It is acknowledged that perceived need does not equate to actual need. Nevertheless, this indicator comes closest to providing information on the non-financial support required by primary carers. Perception measures are not new in economics either and are the basis of utility theory.

The terms used in this paper are clarified in Text Box 1.

\section{Background}

In 2003, mental illnesses were among the ten leading causes of disease burden in Australia, accounting for $13 \%$ of the total burden of disease (Australian Institute of 
Health and Welfare 2006). Compared to people with a physical disability, those with a mental disability require a different set of services to allow them to participate in the community and conduct their activities of daily living (Williams \& Doessel, 2001). While physically ill people can require nursing services, they are usually capable of judgment and decision-making. Those suffering from a mental illness, however, often rely on their informal carers to make decisions and judgments. The duties of these informal carers can involve behavioral management issues, and time devoted to the activities of daily living and liaising with the legal and criminal justice systems (Lefley 1997).

Studies have shown that caring for a relative with a mental illness is burdensome and demanding (Williams \& Doessel 2001; Donaldson \& Burns 1999; Diwan 1999; Holmes \& Deb 1998; Snell 1985). This partly explains the perception of inadequate levels of effective and consistent care faced by those suffering from persistent mental illness (Belcher 1993; Holmes \& Deb 1998).

This study extends the work of previous research in several ways. First, although investigations have drawn attention to resource inadequacies in the wider community for people with a mental illness (Mental Health Council of Australia, 2000; Lamb \& Bachrach 2001; Groom et al 2003; Palmer 2005), no Australian research has investigated the impact of disability type (mental and physical) on the primary caregivers need for assistance after the influence of other variables have been removed from the analysis. Yet such an investigation is useful in the negotiation of scarce health resources. Second, in this study need is measured in terms of perceived rather than 
normative need, where normative need refers to accepted standards with which resource allocation can be compared (Kettner el al 2008). Since the caregivers and the recipients under investigation possess highly individualised needs, perceived need rather than a finite measure is best for comparisons among groups. Third, the majority of studies that investigate informal care tend to use a relatively small sample of individuals often sourced from regional surveys (e.g. Holmes and Deb 1989). Often investigations are confined to caregivers of either older people (e.g. Weiss et al 2005; Broe et al 2002; Snell 1985) or recipients with a particular disabling condition (e.g. Holmes and Deb 1989). Findings from a national data set provides a balance to the existing literature that is dominated by regional studies. This allows the conclusions of this study to be generally applied for policy purposes.

\section{Theory}

Williams and Doessel (2003) provide a thorough analysis of mental health care based on the household production function and the consumer demand theory associated with Ironmonger and Lancaster. The concepts are applied to the production of health status through care at home. In brief, the improvement of health status requires an alleviation of symptoms such as pain, either psychological or physical, and a reduction in disabilities. Thus health status is a function of symptom alleviation and disability reduction (Williams and Doessel 2003).

Inputs such as informal care and formal treatments and therapies alleviate the individual's symptoms and reduce disabilities leading to an improvement in the health status of the individual (Williams and Doessel 2003). It is in the family that 
individualistic motives for economic activity are overcome to meet the needs of other family members. Typically distribution within the family accords to the specific needs of each member of the family (Aguirre 2001). The deinstitutionalization of the mental health system places greater emphasis on the informal carer as an input (human capital) in the production of health status.

\section{Methods}

The Survey of Disability, Ageing and Carers (SDAC), conducted by the Australian Bureau of Statistics throughout Australia in the months of June to November 2003, covered people in both urban and rural areas in all states and territories. Trained interviewers collected the household component of the data survey. Where possible, a personal interview was conducted with people identified as either disabled, and/or aged 60 years and over, and those providing care to them (ABS 2003).

\section{Data Analytic procedures}

For weighting purposes, the 2003 SDAC (using data collected from the household sample of 36088 persons) was benchmarked to the estimated population at 30 June 2003, based on results from the 2001 Census of Population and Housing. The subsample used in this study consisted of those 526 persons ((mental (76) and physical (450) disability) from the Confidential Unit Record Files (CURF) dataset that met the criteria for this research. Since the sampling used a complex multistage method, ABS supplied the weightings (person weights) in the SDAC CURF dataset. This dataset that could be used in any statistical analysis (with any subset of the data since survey weights indicate how many population units are represented by the sample unit) to 
compensate for sample selection features such as selection bias, or cluster sampling with probability proportional to size (ABS Technical Report 2003). The rescaled weights were also applied within a weighted binary logistic regression analysis ${ }^{1}$ (seeWinship \& Radbill 1994).

\section{Logistic Regression}

A link is determined between the recipient's disability type, either mental or physical, and the carers need for assistance after other influences from eleven independent variables, chosen as appropriate from the extant literature (Holmes \& Deb 1998; Spruytte et al 2002; Banerjee et al 2003; Broe 2002) have been controlled for in the analysis. The model is therefore conditional on the values of these other significant covariates. As a discriminant tool, logistic regression is used to predict group membership (Tabachnick \& Fidell 1996 p25), i.e. carer’s unmet need for assistance or otherwise, as well as to test the significance of the various hypothesized predictor variables and their interactions with respect to that need.

Initially, the full model linear predictor to be tested is

$\mathrm{N}_{\mathrm{i}}=\beta_{0}+\beta_{1} \mathrm{MC}_{\mathrm{i}}+\beta_{2} \mathrm{X}+\varepsilon_{\mathrm{I}}$

Where the linear predictor $\mathrm{N}_{\mathrm{i}}$ is an index of a carer's perception of need, viz. the log of the odds of that need being unmet. MC represents the main disabling condition of the recipient, 1 if mental, 0 if physical. $\mathrm{X}$ is the vector of variables that affect a carer's perception of need. These inlcude carer characteristics such as gender ( 1 if male, 0 female), age (ordinal age-group from 15years: $1=15-19,2=20-25$, etc. treated as a continuous variable), employment status (1 if full time, 2 if part time, 3 if unemployed 
and looking for full time employment, 4 if not in the labour force), and duration of care (1 if less than 1 year of care; 2 through 8 in five year intervals; 9 if 35 years and over). Dichotomous variables (1 if yes, 0 if otherwise) include assistance received, fall back informal carer and children under 15.

The model includes recipient characteristics identified in previous research as impacting on primary care (Shaw \& Dorling 2004; Weiss et al, 2005; Broe 2002; Holmes \& Deb 1998; Banerjee et al 2003). These characteristics are gender, age, disability status (1 if profound, 0 if severe) and the relationship of the primary carer to the main recipient (spouse, parent, offspring, friend/neighbor/other relative, 'spouse' is the referent).

In addition a number of 2-way interactions between the various main effects were tested and added to the model if significant, and other main effects that proved not to be significant were dropped from the model. The variable "fallback informal carer" contained 62 (11.1\%) missing cases. The program performed the regression without these cases, leaving a total of 464 in the analysis.

\section{Data}

The dependent variable was derived from the primary carer's perceived need for assistance variable reported in the national data set (ABS 2003). This four categorical variable was transformed to a dichotomous variable: ' 1 ' for 'unmet need of assistance' and ' 0 ' for 'needs met'. 'Unmet need' refers to a situation where either a)the primary carer receives assistance but requires further assistance or b) does not receive assistance and requires assistance. 'Needs met' refers to a situation where the primary carer either 
a) does not receive assistance and does not need assistance or b) Receives assistance and does not need further assistance.

The term government pension requires clarification. The carer allowance is a supplementary payment for carers who provide daily care and attention for adults with a disability, severe medical condition or people who are frail and aged. In this study it is assumed that all primary carers of recipients with severe and profound disabilities receive this payment. In constrast, the carer payment is an income support payment for people who are unable to support themselves through participation in the workforce while caring for someone with a disability, severe medical condition or who is frail and aged (Australian Government 2007). Unlike the carer allowance, the carer payment is income and asset tested and classified as government pension. The carer allowance may be paid on top of carer payment.

It is an assumption of this paper that carers of people with either mental or physical disabilities, if eligible, receive similar levels of government assistance (formal and informal). Differences in the perception of need therefore implies that greater care burdens may be placed on a certain group of carers because resources are either limited or inappropriate.

The significant and highly correlated $(\mathrm{p}<.001)$ variables "employment status", and "income" led to the exclusion of the latter from the model after firstly modelling them separately. Employment status as a categorical variable - representing either those not in the labour force, part time employed, full time employed, or looking for full time 
employment - replaced the dichotomous variable, income, that represented the receipt of a government pension or not. The majority of those receiving a full government pension are represented in the 'not in the labour force' category of employment status.

Since the duration of care may impact on the need for assistance this variable was added to the model. Information about the presence of other family members in the household was indirectly captured by including the variable that identified a fall back carer. A fall back carer is not a formal provider. The variable 'carer assistance received' is also added which captured formal and informal assistance since it is not unusual for families to have a combination of both. Data relating to family income was not available for the analysis.

\section{Results}

Descriptive statistics for the weighted population are presented in Tables 1, 2 and 3. Since the ABS already applied the correct weightings to estimate the total population with the selected characteristics, the statistical tests were not applied to compare the percentages in the descriptive statistics reported here. These figures are treated as population figures. To ensure the integrity of the data, the population figures were crosschecked against the total Australian population figures provided by the ABS (ABS 2003).

The regression analysis tests the effect of the disabling condition on carers' perception of need, conditional on the other relevant covariates. 
Profile of the Non-institutionalised Care Recipients and their Primary Informal Carers For comparison, care recipients and their primary carers are split into two populations, mental disabilities ( $\mathrm{N}=38999)$ and physical disabilities $(\mathrm{N}=235991)$. Consistent with the summary findings reported by the ABS, the mental and physical categories are derived from the main disabling condition variable (ABS 2003).

Comparison of the care recipient populations, mental and physical, is presented in Table 1. Of those reporting mental disability as the main disabling condition, males outnumber females, with a greater proportion of people in the mental category (71\%) aged between 15 and 65 years. By contrast females outnumber the males in the physical group, with $57 \%$ of this group aged 65 and over.

Fewer of those with a physical disability report the existence of a fallback carer (49\%) compared to those with a mental disability (53\%). The greater proportion of parents caring for people with a mental disability (38\%, compared with $7 \%$ of people with a physical disability) may explain the difference (refer Table 2).

\section{INSERT TABLE 1 HERE}

Primary informal carers of people with profound and severe disabilities are typically younger than 65 years of age, female and receive a government pension. The analysis supports previous studies (Holmes \& Deb 1998; Winfield \& Harvey 1994) that those with a mental disability are more likely to be cared for by parents. Those with a physical disability tend to be cared for by a spouse or partner. 
Table 2 also documents greater adversity among those caring for people with a mental disability. For instance, of this primary carer group, 30\% report inadequate assistance in their role as carer compared to $17 \%$ of other primary carers. Also a greater proportion of these primary carers report a change in their physical and emotional well being due to their caring role (37\%) compared to other primary carers (26\%). A greater proportion of carers of those with physical disabilities (71.3\%) do not participate in the labour force compared to the other carers of those with mental disabilities (60.3\%), possibly reflecting the older cohorts of carers within that group.

\section{INSERT TABLE 2 HERE}

There is consensus within the literature that disability type and disability status impacts on the level of care provided to individuals. Table 3 presents carers' perception of need for assistance by disability type and disability status. Disability status of those restricted in their core activities is segregated into profound and severe. Across the disability type and status categories, again a greater proportion of carers of those with a mental disability report inadequate or unmet assistance compared to carers of those with a physical disability. Specifically, within the profound category, 33.6\% of carers of those with a mental disability report inadequate assistance, compared to $23.5 \%$ of carers of those with a physical disability. The gap widens for carers of people with severe disabilities. Here $21.6 \%$ of the mental group report unmet assistance compared to $8.3 \%$ of others. 
INSERT TABLE 3 HERE

The Effect of Disabling Condition on the Carers' Perception of Need for Assistance

Results from model (1) with no interaction effects are shown in Table 4. This model resulted in a Nagelkerke $\mathrm{R}^{2}$ of $27 \%$. It has a model Chi-Square value (from the Log Likelihood statistic) of 87.0 with 24 degrees of freedom (df) that is strongly significant $(\mathrm{p}<.001)$ because of the large sample size. A non-significant lack-of-fit for the model is reported by the Hosmer Lemenshow (H-L) statistic as 6.8 with $8 \mathrm{df}(\mathrm{p}>0.5)$.

\section{INSERT TABLE 4 HERE}

From Table 4 the odds ratio results reveal that carers of those with a mental disability are $2.7(1.3-5.6)^{2}$ times more likely to have their need for assistance unmet compared to carers of those with a physical disability $(\mathrm{p}=0.008)$. If community health resources were allocated appropriately and equitably between the mental and physical group the odds ratio would not be significantly different from 1.

Other significant results include that if the primary carer is a parent of the person with the disability they are 4 times (1.3-12.4) more likely to need assistance than if the primary carer is a spouse $(\mathrm{p}=0.015)$. If the primary carer is an adult offspring of the disabled, they are 2.3 times (0.9-6.1) more likely to need assistance than if the primary carer is a spouse, with a borderline level of significance $(\mathrm{p}=0.10)$. 
Individuals who have a fall-back carer are about $40 \%(0.2-0.7))$ as likely to need assistance $(p=0.002)$ than those without a fallback carer. When another variable that included extra information about the living arrangements of the fall back carer (where they existed) replaced this one, it showed no significant difference as to whether the fallback carer lived with the main recipient of care or not.

Carers employed full time and those employed part time are more than three times (1.46.8; 1.4-7 respectively) as likely to need assistance than carers not in the labour force ( $\mathrm{p}=0.005$ for both categories). Those whose disability status is 'profound' i.e. profoundly restricted in core activities, are 2.4 times (1.3- 4.7) more likely to need assistance compared with disability status 'severe' i.e. severely restricted in core activities $(p=0.007)$. The odds ratio for Unmet Need for Assistance increases, on average, by $13 \%(0-28 \%)$ with each successively older 5-year age group starting at 1519 years $(\mathrm{p}<0.06)$. Those receiving assistance are 1.9 times $(1.1-3.4)$ more likely to need assistance than those not receiving assistance $(\mathrm{p}<0.03)$.

Note that model (1) is better used for explanation rather than prediction. The data sample is heavily weighted towards cases needing assistance compared with cases not needing assistance ( $\sim .5$ to 1 ). This leads to models with high probability Type I errors. This means that they bias fit toward the most popular category, that is, those not needing assistance, thus reducing the Type II error. So overall classification is good at $84 \%$ but at the expense of the Type I error. Hence, it is better at predicting 'no-need' than 'need'. The full model has a 69.6\% (64/92) Type I error (predicting 'no need' 
when there actually is a need for assistance) and just 3\% (11/375) probability Type II error (predicting 'needs assistance' when there is no need.).

\section{A Model with Interaction Effects}

With a number of two-way interactions included in a forward stepwise regression, modifications need to be made to the main effect conclusions in model (1) without interaction effects as the significant interactions can account for and explain further the formerly significant main effects. Alternatively, significant interactions can also explain the lack of significance of other main effects since sometimes only certain levels of categorical variables interact significantly and others do not, thus clouding the picture that emerges.

\section{INSERT TABLE 5 HERE}

The final forward stepwise selection regression model, reported in Table 5, resulted in a Nagelkerke $\mathrm{R}^{2}$ of $28 \%$. It has a model Chi-Square value of 89.3 with 8 degrees of freedom that is strongly significant $(\mathrm{p}<0.001 \sim 0)$. A non-significant lack-of-fit for the model is reported by the Hosmer Lemenshow (H-L) statistic as 5.2 with $8 \mathrm{df}(\mathrm{p}>0.7)$.

The most important differences in the results of the interactions model compared to model (1) are described below in order of p-value, smallest to largest.

Adult children as carers of those with mental disabilities are around 110 times (7-1723) more likely to need assistance than a carer who is either a spouse, other relative, friend 
or neighbor - of either disability type, or an adult offspring carer of a physically disabled patient $(\mathrm{p}=0.001)$. This significant interaction accounts for the lowered statistical significance $(\mathrm{p}=0.101)$ of the main effect "carer offspring of main recipient of care” in model (1) as the effect was diluted by offspring carers of the physically disabled group generally not needing further assistance.

Carers who are parents of people with either a mental or physical disability are 6.2 times (2.2-17.3) more likely to need assistance than all other primary carers other than the offspring of mentally disabled patients $(\mathrm{p}<0.001)$.

Other significant main effects within the interactions model increased slightly from their model (1) counterparts in their effect on carers' need for assistance. Carers employed in the labour force full time are 4.3 times (2.1-8.7) more likely to need assistance compared to carers not in the labour force $(\mathrm{p}<0.001)$ and carers registered in part time employment are 3.6 times (1.7-7.5) more likely to need assistance compared to carers not in the labour force $(p=0.001)$. The odds ratio for Unmet Need for Assistance increases, on average, by $19 \%$ with each successively older 5-year age group $(\mathrm{p}=0.001)$. Other significant main effects that did not change much from their model (1) counterparts are that carers receiving assistance are still nearly twice as likely to need assistance than those not receiving assistance $(\mathrm{p}=0.02)$. Those having a fall-back carer are still about $60 \%$ less likely to need assistance tha those without a fall-back carer $(p=0.002)$ and care recipients who are profoundly restricted in core activities are 2.3 times more likely to need assistance compared with those severely restricted $(p=0.01)$. 
No significant interaction exists between receiving assistance and type of disability. Other variables that do not figure significantly in the models that were tested are age and gender of carer, income and gender of recipient, remoteness of address (city, regional, other) and duration of care.

\section{Discussion and Conclusion}

The Carers of People with Mental Illness project (MHCA 2000) and later the Out of Hospital, Out of Mind project of 2003 (Groom et al 2003) drew attention to resource inadequacies for people with a mental illness living within the community. While these projects highlight the care burdens of this disability, a case is made for improved services by placing it against the context of the physical disability group. A comparison study of the assistance needs of primary informal carers between the two groups offers an opportunity to identify resource inequalities. These comparisons provide a basis for negotiation with policy makers to equalize and improve the allocation and prioritization of public funds.

Analysis of the data revealed that the disabling condition of the recipient did impact on the carers' perception of need for assistance. Yet if support services were equitably allocated between the groups of people with a physical and mental disability, the disabling condition would have little or no impact on the model. Carers of those with a mental disability were 2.7 times more likely to report their care needs unmet compared to carers of those with a physical disability. This is interesting given that carers of people with a mental disability were more likely to report the existence of a fall back carer residing in the same household. This implies that within this disability group, 
although informal care may be adequate, as suggested by the availability of a live-in fall back carer, formal services are not ${ }^{3}$.

Further analysis of the data using interactions revealed that the significant difference in perceived assistance between carers of the mental versus physical group were mainly driven by the adult children of those with mental disabilities. Adult children as carers of this group were around 110 times more likely to need assistance compared to a spouse, other relative, friend or neighbor - of either disability type, or compared to adult children who care for their physically disabled parents. A possible explanation is that adult children who are carers face greater opportunity costs in terms of paid employment and this may be reflected in their expectations. Also witnessing the loss of dignity of a parent is difficult. The care burden associated with dementia, the main disabling condition for $26 \%$ of Australians aged 85 and over (ABS, 2003), provides another explanation. Caring for an older person with dementia, for example, requires 24 hour care. Episodes of intense care are often sporadic and unpredictable.

The Mental Health Council of Australia (2000) asserts that if formal service delivery for consumers operated at the levels expected within the National Standards for Mental Health Services (Commonwealth of Australia 1997) little difference should exist in the resources available to people with either mental or physical disabilities. If equity is measured in terms of perceived need rather than finite resources a case is made here that an inequitable distribution of resources exist between the two carer groups, with primary carers of people with a mental disability experiencing greater burdens in care. 
Two opposing reasons are put forward for the reported difference in the need of assistance between the two carer groups. One view is that those suffering a physical illness have greater access to formal services (Groom et al 2003; MHCA 2000). Additional analysis of the ABS data regarding respite care (a major category of formal service) reported unmet needs for $21 \%$ of care recipients with a mental disability compared to $13 \%$ of care recipients with a physical disability. This adds weight to the conclusions arrived by the Mental Health Council of Australia (2006) that individuals and their families are unable to access mental health services when needed because of the lack of investment and accountability following the de-institutionalization process.

An alternative view is that access to formal resources between the two disability groups are similar, but those suffering a mental disability require either a different set of resources (Lefley 1997; Williams \& Doessel 2001) or a greater quantity of resources (Donaldson \& Burns 1999; Diwan 1999). The issue might be more fruitfully resolved if different models of need are used by policy makers. At present, health policy makers are not factoring in either perceived or relative need with regard to service delivery to carers of people with a mental disability.

Whatever the reason for perceived differences in need, there is clearly a case for prioritizing resources towards carers of people with a mental disability in Australia. This is best achieved when programs work in partnership with family and friends to improve the circumstances of people with disabilities and their carers. Furthermore, recognizing that the two carer groups (either mental or physical) face either different levels and or types of burden implies that service delivery to this group needs to be of a 
different type or quality to meet the diverse needs of carers and their recipients. A discussion on the care alternatives that would meet the needs of the recipients and alleviate the burden of caregivers was beyond the scope of this study. A future study will investigate this issue.

This study was confined to care recipients aged 15 years and older with a profound or severe disability and their primary carers. Investigations of people experiencing moderate to mild disabilities provide further research opportunities. Since the variable assessing unmet need is dichotomous, the analysis could not investigate the extent of unmet need for assistance. This is a limitation of the study. The authors suspect that the receipt of assistance is endogenous. This will be addressed in future research. Furthermore, an understanding of the reasons for the perception of inadequate assistance would contribute to the literature.

\section{References}

Aguirre, M. (2001), "Family, economics and the information society. How are they affecting each other?” International Journal of Social Economics, Vol. 28, No. 3, pp. 225-247.

Australian Bureau of Statistics (2003), Disability, Ageing and Carers: Summary of Findings, Australian Bureau of Statistics, Canberra, Australia.

Australian Government Productivity Commission (2005), Economic Implications of an Ageing Australia, Productivity Commission Research Report, Canberra, Australia.

Australian Institute of Health and Welfare (AIHW) (2006), Australia's Health 2006, Australian Institute of Health and Welfare, Canberra, Australia.

Australian Government (2007), Centerlink.

[http://www.centrelink.gov.au/internet/internet.nsf/payments/carer_allow_adult.htm] accessed July 2007. 
Banerjee, S., Murray, J., Foley, B. and Atkins, L. (2003), "Predictors of institutionalization in people with dementia”, Journal of Neurology, Neurosurgery and Psychiatry, Vol. 74, No. 9, p. 1315.

Beilhorz, P., Considine, M. and Watts, R. (1992), Arguing About the Welfare State: The Australian Experience, Allen and Unwin, Sydney.

Belcher, J. (1993), “The trade-offs of developing a case management model for chronically mentally ill people”, Health and Social Work, Vol. 18, No. 1, pp. 20-32.

Bradshaw, J. (1972), “The concept of social need”. New Society, Vol. 30, pp. 640-643.

Broe, G., Grayson, D., Waite, L., et al. (2002), "Determinants of service use among the elderly: the Sydney older persons study”, Australasian Journal on Ageing, Vol. 21, No. 2, pp. 61-66.

Commonwealth of Australia (1997), National Standards for Mental Health, Commonwealth of Australia, Canberra, Australia.

Courtney, M., Minichiello, V. and Waite, H. (1997), “Aged care in Australia: A critical review of the reforms”, Journal of Aging Studies, Vol. 1, No. 30, p. 229.

Diwan, S. (1999), “Allocation of case management resources in lone-term care: predicting high use of case management time”, The Gerontologist, Vol. 39, No. 5, pp. 580-590.

Donaldson, C. and Burns, A. (1999), “Burden of Alzheimer’s disease: Helping the patient and the caregiver”, Journal of Geriatric Psychiatry and Neurology, Vol. 12, pp. 21-28.

Groom, G., Hickie, I. and Devenport, T. (2003), Out of Hospital, Out of Mind! A report detailing mental health services in Australia in 2002 and community priorities for national mental health policy 2003-2008, Mental Health Council of Australia, Canberra.

Healy, J. (2002), “The care of older people: Australia and the United Kingdom”, Social Policy and Administration, Vol. 36, No. 1, pp. 1-19.

Holmes, A. and Deb, P. (1998), "Factors influencing informal care-giving”, The Journal of Mental Health Policy and Economics, Vol. 1, pp. 77-87.

Kendig, H., McVicar, G. and Reynolds, A. (1992), The Victorian Linkages Evaluation. Department of health, housing and community services and community services Victoria, Melbourne.

Kettner, P., Moroney, R. and Lawrence, M. (2008), Designing and Managing Programs: An Effectiveness Based Approach, Sage Publications, California. 
Lamb, R. and Bachrach, L. (2001), ”Some perspectives on deinstitutionalization”, Psychiatric Services, Vol. 52, pp. 1039-1045.

Lefley, H. (1996), Family Caregiving in Mental Illness, Sage, Thousand Oakes.

Mental Health Council of Australia (MHCA) (2000), Carers of People with Mental Illness Project, MHCA, Canberra.

Mental Health Council of Australia (MHCA) (2006), Time for Service. Solving Australia's Mental Health Crisis, Mental Health Council of Australia, Canberra.

Palmer, M. (2005), Inquiry into the Circumstances of the Immigration Detention of Cornelia Rau Report. Commonwealth of Australia, Canberra. [www.minister.immi.gov.au/media_releases/media05/palmer-report.p]

Queensland Government (2004), HACC Workforce Skills Development Strategy Information Paper. Queensland Health, Brisbane.

Shaw, M. and Dorling, D. (2004), "Who cares in England and Wales? The positive care law: cross-sectional study”, British Journal of General Practice, Vol. 54, No. 509, pp. 899-904.

Snell, M. (1985), “Community care for the elderly: costs and dependency”, Social Science and Medicine, Vol. 20, No. 2, pp. 1313-1318.

Spruytte, N., Van Audenhove, C., Lammertyn, F. and Storms, G. (2002), “The quality of the caregiving relationship in informal care for older adults with dementia and chronic psychiatric patients”, Psychology and Psychotherapy: Theory, Research and Practice, Vol. 75, pp. 295-311.

Tabachnick, B. and Fidell, L. (1996), Using Multivariate Statistics. Third Edition, HarperCollins, Northridge.

Victorian Parliament (1997), Inquiry into Planning for Positive Ageing. Family Community Development Committee, Victorian Government, Melbourne.

Ware, J., Snow, K., Kosinski, M., and Gandek, B. (2000). SF-36 Health Survey: Manual and Interpretation Guide. Lincoln: Quality Metric Inc.

Weiss, C., Gonzalez, H., Kabeto, M. and Langa, K. (2005), ”Differences in amount of informal care received by non-Hispanic whites and Latinos in a nationally representative sample of older Americans”, Journal of the American Geriatrics Society, Vol. 53, No. 1, pp. 146-152.

Williams, R. and Doessel, D. (2001), The Economics of Mental Health Care, Industry, 
Government and Community Issues, Ashgate, Aldershot.

Williams, R. and Doessel, D. (2003), “The multiple dimensions of mental health services: a conceptual framework”. International Journal of Social Economics, Vol. 30, No. 9, pp. 1000-1033.

Winefield, H. R., and Harvey, E. J. (1994), “Needs of family caregivers in chronic schizophrenia”. Schizophrenia Bulletin, Vol. 12, No. 4, pp. 557-566.

Winship, C. and Radbill, L. (1994), “Sampling weights and regression analysis", Sociological Methods and Research, Vol. 23, No. 2, pp. 230-257.

\section{Acknowledgement}

The authors would like to acknowledge the help, with regard to the statistical analysis, given by Adrienne Kirby of the NHMRC Clinical Trials Centre at Sydney University, and by Daniel Elazar, Australian Bureau of Statistics, Canberra. The authors also wish to thank the staff of the Griffith Business School for their helpful suggestions at a seminar presentation.

\section{Text Box 1 \\ Definitions}

Several terms used in this paper are clarified below.

Mental disability: Disabling conditions include psychoses and mood affective disorders, neurotic, stress-related and somatoform disorders and intellectual and development disorders.

Profound Disability: A care recipient possesses a profound disability when they are unable to do or always need help with a core activity task in communication, mobility and self-care (ABS, 2003).

Severe Disability: A care recipient possesses a severe disability when sometimes they need help with a core-activity task, has difficulty understanding or being understood by family or friends, can communicate more easily using sign language or non-spoken forms of communication (ABS, 2003).

Primary Carer: A primary carer, aged 15 or over, provides the most informal assistance to the care recipient. The assistance is ongoing for at least six months and includes communication, mobility and self care (ABS, 2003). 
Table 1

Characteristics of the Non-institutionalised Main Recipients of Care with Profound and Severe Disabilities, Aged 15 and Over, Australia, 2003

\begin{tabular}{|c|c|c|c|c|}
\hline \multicolumn{3}{|l|}{ Recipient of Care } & Mental & Physical \\
\hline \multirow{2}{*}{ Gender } & 1. & Male & 53.3 & 46.5 \\
\hline & 2. & Female & 46.7 & 53.5 \\
\hline \multirow[t]{2}{*}{ Age } & 1. & 15 - 65 years & 71.4 & 42.6 \\
\hline & 2. & $65+$ years & 28.6 & 57.4 \\
\hline Main source of income & 1. & Government pension & 75.6 & 78.9 \\
\hline \multirow[t]{2}{*}{ Informal carer available } & 1. & Yes & 53.4 & 48.7 \\
\hline & 2. & No fallback carer/don’t know & 46.6 & 51.3 \\
\hline \multirow[t]{2}{*}{ Disability status } & 1. & Profoundly restricted & 65.8 & 59.8 \\
\hline & & Severely restricted & 34.2 & 40.2 \\
\hline
\end{tabular}

Source: Survey of Disability, Ageing And Carers (ABS 2003). 
Table 2

Characteristics of the Primary Care Givers of the Non-institutionalised People Aged 15 and Over with Profound and Severe Disabilities, Australia, 2003

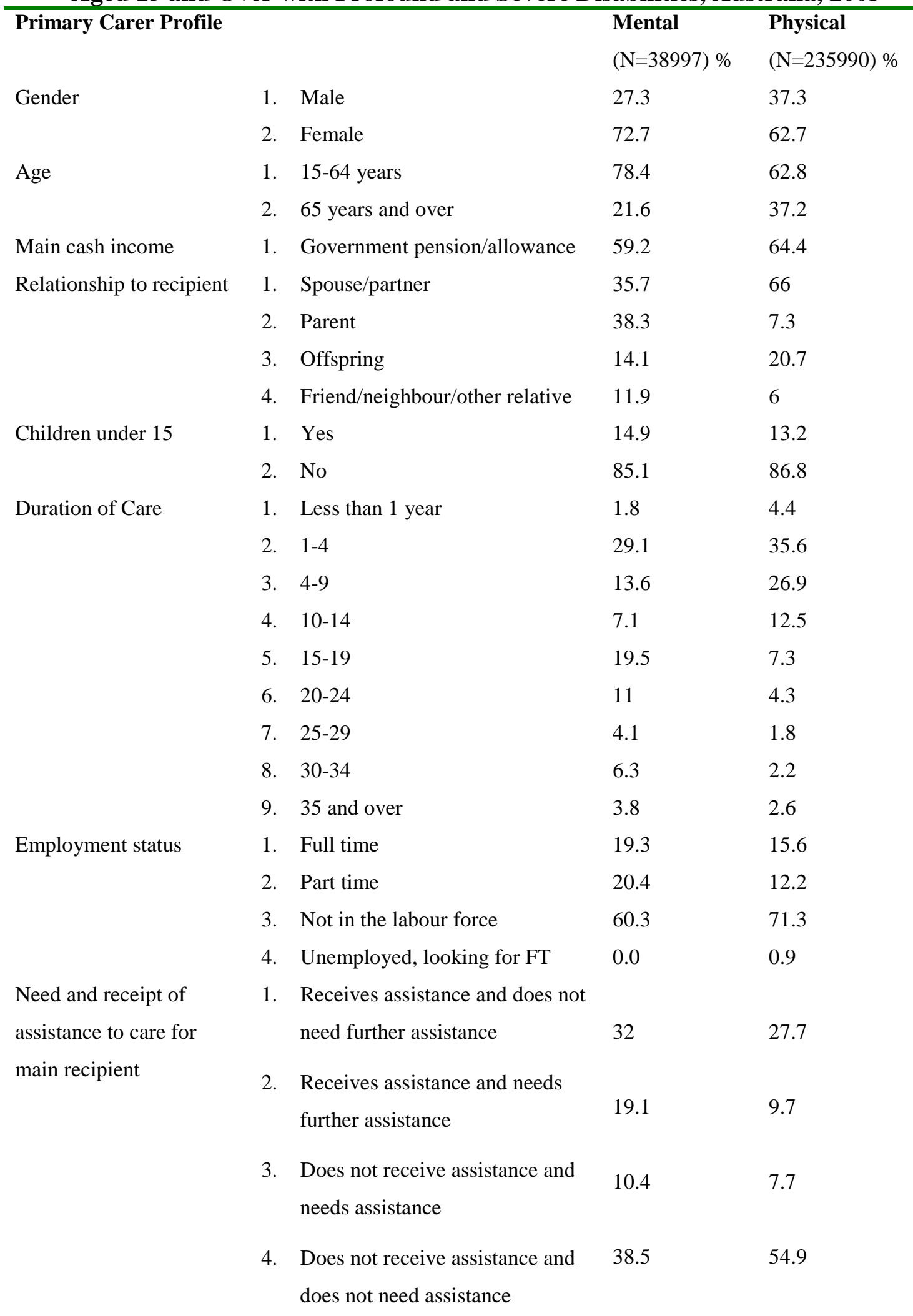

Source: Source: Survey of Disability, Ageing And Carers (ABS 2003) 
Table 3

Primary Carer Adequacy of Assistance by Disability Status and Type, Australia, 2003

\begin{tabular}{llll}
\hline Disability status & Disability type & Adequacy of assistance & Percent of persons \\
\hline Profound & Mental & Inadequate & 33.6 \\
& & Adequate & 66.4 \\
Profound & Physical & Inadequate & 23.5 \\
& & Adequate & 76.5 \\
Severe & Mental & Inadequate & 21.6 \\
& & Adequate & 78.4 \\
Severe & Physical & Inadequate & 8.3 \\
& & Adequate & 91.7 \\
\hline
\end{tabular}

Source: Survey of Disability, Ageing and Carers (ABS 2003) 
Table 4

Regression Analysis Explaining Carers' Unmet Need for Assistance

Odds RatioEstimate $^{4} \quad 95 \%$ Confidence Limits on OddsRatio ${ }^{5}$

\begin{tabular}{|c|c|c|c|}
\hline Disabling condition & $2.69 * *$ & 1.29 & 5.58 \\
\hline Assistance received & $1.9 *$ & 1.07 & 3.38 \\
\hline Gender of recipient & 1.01 & 0.52 & 2.0 \\
\hline $\begin{array}{l}\text { Age of recipient (continuous } \\
\text { measure) }\end{array}$ & $1.13^{*}$ & 1.0 & 1.28 \\
\hline Gender of carer & 1.58 & 0.82 & 3.07 \\
\hline Age of carer & 1.0 & 0.87 & 1.17 \\
\hline Fall back carer & $0.4 * *$ & 0.23 & 0.7 \\
\hline Disability status & $2.43 * *$ & 1.27 & 4.66 \\
\hline Relation ${ }^{\mathrm{a}}$ - parent & $4.02 * *$ & 1.31 & 12.36 \\
\hline Relation ${ }^{\mathrm{a}}$ - son/daughter & 2.28 & 0.85 & 6.11 \\
\hline Relation ${ }^{\mathrm{a}}$ - other & 0.77 & 0.21 & 2.82 \\
\hline Employ status $^{\mathrm{b}}-\mathrm{F} /$ time & $3.09 * *$ & 1.40 & 6.8 \\
\hline Employ status ${ }^{\mathrm{b}}-\mathrm{P} /$ time & $3.18^{* *}$ & 1.43 & 7.08 \\
\hline Employ status ${ }^{\mathrm{b}}$ - unem & 0.00 & .00 & \\
\hline Children under 15yrs & 1.06 & 0.48 & 2.34 \\
\hline \multicolumn{4}{|l|}{ Dur of care ${ }^{c}$} \\
\hline $1-4$ & 1.1 & .09 & 13.94 \\
\hline $4-9$ & 1.63 & .21 & 12.43 \\
\hline $10-14$ & 1.54 & .2 & 11.88 \\
\hline $15-19$ & 1.7 & .2 & 14.02 \\
\hline $20-24$ & 0.69 & .08 & 6.34 \\
\hline $25-29$ & 1.29 & .13 & 12.7 \\
\hline $30-34$ & 6.98 & .49 & 99.25 \\
\hline 35 and over & 1.66 & .14 & 19.62 \\
\hline don’t know & 3.45 & .31 & 38.51 \\
\hline Nagelkerke R square & \multicolumn{3}{|c|}{$27 \%$} \\
\hline
\end{tabular}

${ }^{\mathrm{a}}$ Referent is spouse. ${ }^{\mathrm{b}}$ Referent is not in labour force. ${ }^{\mathrm{C}}$ Referent is less than 1 year.

**Significant at 0.01 level (two tailed)

* Significant at 0.05 level (two tailed) 
Table 5

Interaction Model - Carers' Unmet Need for Assistance

Odds Ratio Estimate $\quad 95 \%$ Confidence Limits on Odds Ratio

$\begin{array}{lccc}\text { Assistance received } & 1.88^{* *} & 1.09 & 3.23 \\ \text { Age of recipient } & 1.19^{* *} & 1.07 & 1.31 \\ \text { Fall back carer } & .41^{* *} & .24 & .72 \\ \text { Employ status a - F/time } & 4.3^{* *} & 2.13 & 8.7 \\ \text { Employ status }{ }^{\mathrm{a}}-\mathrm{P} / \mathrm{time} & 3.56^{* *} & 1.69 & 17.27 \\ \text { Relation - parent } & 6.12^{* *} & 2.22 & 1722.74 \\ \text { Disabling condition } \mathrm{x} & 110.02^{* *} & 7.03 & 4.3 \\ \text { Relation son/daughter } & & & 1.23 \\ \text { Disability status } & 2.3^{* *} & & \\ \text { Nagelkerke R square } & 28 \% & & \end{array}$

${ }^{\mathrm{a}}$ Referent - those not in labour force

**Significant at 0.01 level (two tailed)

* Significant at 0.05 level (two tailed) 
1 When raw weights are included in a weighted model, all estimates are statistically significant, so a scaled proportion of the survey weights was used so that the rescaled weights sum to the sample size. This often gives correct estimates but slightly biases variances (private communication ABS).

2 The 95\% confidence limits are bracketed.

3 Additional analysis in one of the major categories of formal service, respite care, revealed unmet needs in this area of care for $21 \%$ of care recipients with a mental disability compared to $13 \%$ of care recipient with physical disabilities.

4 Note that an odds ratio above 1.0 refers to the odds that the dependent $=1$ in binary logistic regression. The closer the odds ratio is to 1.0, the more that predictor's categories (eg. male and female for gender) are independent of Unmet Need for Assistance, with 1.0 representing full statistical independence.

5 The 95\% confidence interval (CI) around the logistic regression coefficient is plus or minus 1.96*ASE, where ASE is the asymptotic standard error of logistic $\mathrm{b}$. If this CI covers 1 then it is quite likely that the predictor in question is independent of the variable, Unmet Need for Assistance, so that variable is not considered a useful predictor in the logistic model. 